Article

\title{
Anti-Aging Efficacy of Melatonin-Based Cream: Clinical and Instrumental Skin Evaluation
}

\author{
Massimo Milani ${ }^{1, *(D)}$ and Mario Puviani ${ }^{2}$ \\ 1 Medical Department Cantabria Labs Difa Cooper Via Milano 160, 201042 Caronno Pertusella (VA), Italy \\ 2 Medica Plus Dermatology Service, 41100 Modena, Italy; mariopuf@libero.it \\ * Correspondence: massimo.milani@difacooper.com
}

Received: 25 September 2018; Accepted: 10 October 2018; Published: 11 October 2018

\begin{abstract}
Melatonin is a potent mitochondrial, cytoprotective and antioxidant molecule with potentially strong anti-aging properties. Topical melatonin has been shown to improve the clinical signs of skin aging. Melatosphere ${ }^{\mathrm{TM}}$ is a new lipid-based delivery system able to improve stability and skin penetration of melatonin when used in topical formulations. No clinical studies, using objective instrumental data, are available so far regarding the positive effect of Melatosphere ${ }^{\mathrm{TM}}$ in improving wrinkles in women with mild to moderate skin aging. In an open prospective, evaluator-blinded trial, we evaluate the effects on skin texture of two months of treatment with a Melatosphere ${ }^{\mathrm{TM}}$-based cream. Fifteen women aged $>45$ years with mild to moderate facial skin aging (Glogau score 2-4) participated in the trial, after providing their informed consent. An ANTERA 3D computer-assisted skin analysis evaluation for the assessment of coarse and fine wrinkles of the periorbital area and melanin content was performed at baseline and after two months of treatment. An evaluator-blinded Investigator Global Assessment (IGA) of skin elastosis, roughness, level of dyschromia, skin dryness and the presence of actinic damage was also performed at the same time points using a four-grade score from 0 (no sign) to 3 (severe sign). At baseline, the mean (SD) IGA score was 8.2 (1.0). After two months, the IGA score significantly decreased to $4.2(1.4)(49 \%$ reduction) $(p=0.0007)$. ANTERA 3D evaluations showed a significant reduction in the coarse and fine wrinkle volume in the target area of $-31 \%$ and $-18 \%$, respectively. Melanin content was reduced significantly by $-17 \%$. Topical melatonin carried in Melatosphere ${ }^{\mathrm{TM}}$ improves, in the short term, signs of skin aging evaluated clinically and using the ANTERA 3D device in women with mild to moderate skin aging.
\end{abstract}

Keywords: melatonin; skin aging; ANTERA 3D

\section{Introduction}

Several studies have supported the concept that skin is a complete and independent melatoninergic system [1,2] Skin is, in fact, a relevant extra-pineal melatonin (Mel) synthesis organ [3]. Membrane-bound Mel receptors (MT1 and MT2) are expressed in both animal and human skin [4,5]. At the skin level, Mel acts as a relevant antioxidant and cytoprotective substance [6]. In particular, Mel is an active mitochondrial [7], cytoprotective and antioxidant molecule [8]. Mel is both a direct and indirect antioxidant molecule $[9,10]$; it can increase the production of anti-oxidative enzymes like superoxide dismutase [11]. Furthermore, Mel potentiates the activity of Sirtuin 1, an anti-degenerative molecule [12]. Several studies [13,14] support the concept that Mel can prevent skin sun damage when administered before UV irradiation. The photoprotective functions of Mel are also expressed by Mel metabolites like 6-hydroxy melatonin and 5-methoxytryptamine [15]. When applied in organ culture, Mel can reverse UVB-induced damage [16]. Mel could also counteract hyperpigmentation processes through direct and indirect actions [17]. Mel acts through receptor-dependent and receptor-independent mechanisms [18]. At skin level, Mel goes through extensive and rapid different 
metabolic pathways [19], and its metabolites act as free radical scavengers and protectors against oxidative stress [20]. The pleiotropic biochemical actions of Mel and its metabolites at skin level could represent an effective anti-aging strategy [21,22]. The topical application of Mel is considered as meaningful since it can easily penetrate the stratum corneum [23]. A recent clinical trial has shown that topical Mel improves clinical signs of skin aging [24]. Melatonsphere ${ }^{\mathrm{TM}}$ is a new delivery system able to improve stability and skin penetration of Mel when used in topical formulations. In this system, Mel is incorporated into a mixture of two natural oils: Opuntia ficus indica seed oil and Persea gratissima. The final product is carried in an o/w cream. No clinical studies, using objective instrumental data, are available so far regarding the positive effect of Melatosphere ${ }^{\mathrm{TM}}$ cream in improving coarse wrinkles in women with mild-to-moderate skin aging.

\section{Study Aim}

In a pilot, open, prospective, evaluator-blinded trial, we evaluated the effects on skin texture of two months of treatment with a Melatosphere ${ }^{\mathrm{TM}}$-based o/w cream (a cream containing glycerin and $0.1 \%$ melatonin in oleospheres of opuntia ficus indica seed oil and persea gratissima oil) in 15 women aged $>45$ years with mild to moderate facial skin aging (Glogau score $2-4$ ). The study aimed to assess the anti-aging effect of Mel-based cream evaluated using clinical (IGA score) and instrumental (ANTERA 3D CS, Miravex, Dublin, Ireland) tests. The ANTERA 3D CS images system could measure, in an objective and operator-independent manner, the volume of skin depressions (fine and coarse wrinkles) and the melanin content of a pre-specified area [25].

\section{Subjects and Methods}

Fifteen women with mild to moderate facial skin aging were enrolled after providing their informed consent. The subjects also provided their consent to the publication of any pictures. The inclusion criterion was women aged $\geq 45$ years with moderate-severe facial skin aging (Glogau score of 2-4). The exclusion criteria were any acute or chronic skin conditions, which could interfere with the parameters of evaluation and a positive history of allergic contact dermatitis to any of the component of the tested cream. The local institutional review board (IRB; Independent Ethical Committee, c/o Derma Medica, Modena, Italy) approved the trial protocol in February 2018. The study was conducted by following the ethical principles of the Declaration of Helsinki and consistently with the Good Clinical Practice (GCP) regulatory requirements. Compliance with the treatment was evaluated by counting the returned used cream tubes at the final visit. A Melatosphere ${ }^{\mathrm{TM}}$-based cream was applied on the entire face twice daily (2 Finger Tip Units per application) for 2 consecutive months. An ANTERA 3D computer-assisted skin analysis evaluation for the assessment of coarse and fine wrinkles of the periorbital area and melanin content was performed at baseline and after 2 months of treatment. ANTERA 3D is a device which contains a camera for image acquisition and corresponding software for analysis of the skin. It measures an area of $3136 \mathrm{~mm}^{2}(56 \times 56 \mathrm{~mm})$ and can shoot any part of the body. The skin topography and the chromophore concentration are derived from the spatial and spectral analysis of the acquired image data, obtained by illuminating the skin with LEDs of different wavelengths from different directions. ANTERA 3D uses computer to analyze the differences between these images and reconstruct the surface in two and three dimensions. ANTERA 3D images can be used to evaluate skin color, wrinkles, texture, melanin, hemoglobin, pores, depressions, and elevation. A target area, for the ANTERA 3D evaluations, was identified at the baseline visit. An evaluator-blinded Investigator Global Assessment of skin elastosis, roughness, level of dyschromia, skin dryness and the presence of actinic damage was also performed at the same time points using a 4-grade score from 0 (no sign) to 3 (severe sign). A statistical analysis was performed using GraphPad Statistical Software (GraphPad Software, Inc., Version 5, La Jolla, CA, USA). Continuous variables were expressed as mean \pm standard deviation (SD). According to the fact that this was a pilot study, not a formal sample size calculation was performed. We decided to enroll at least 15 subjects. 


\section{Results}

The trial was conducted between March 2018 and September 2018 in an outpatient derma-esthetic clinic. All 15 subjects completed the study. At baseline, the mean (SD) IGA score was 8.2 (1.0). After two months, the IGA score significantly decreased to 4.2 (1.4) (a 49\% reduction) $(p=0.0007$; Wilcoxon test) (Figure 1). In comparison with baseline, ANTERA 3D evaluations at month 2 showed a significant ( $p<0.01$; Wilcoxon Test) reduction in the coarse (Figure $2 \mathrm{~A}, \mathrm{~B})$, fine (Figure $3 \mathrm{~A}, \mathrm{~B})$ and periorbital (Figure 4A,B) wrinkle volume in the target area of $-31 \%,-18 \%$ and $-17 \%$, respectively. The target area coarse wrinkle volume decreased significantly ( $p=0.001$; Wilcoxon Test) from $25.7 \mathrm{~mm}^{3}$ to $17.8 \mathrm{~mm}^{3}$. Target area fine wrinkles decreased significantly from $9.0 \mathrm{~mm}^{3}$ to $6.0 \mathrm{~mm}^{3}(p=0.05$; Wilcoxon Test). The melanin content also reduced significantly ( $p=0.04$; Wilcoxon Test) by $17 \%$ (Figure 5A,B), from 0.6 (0.03) AU to 0.5 (0.03) AU.

\section{IGA Score}

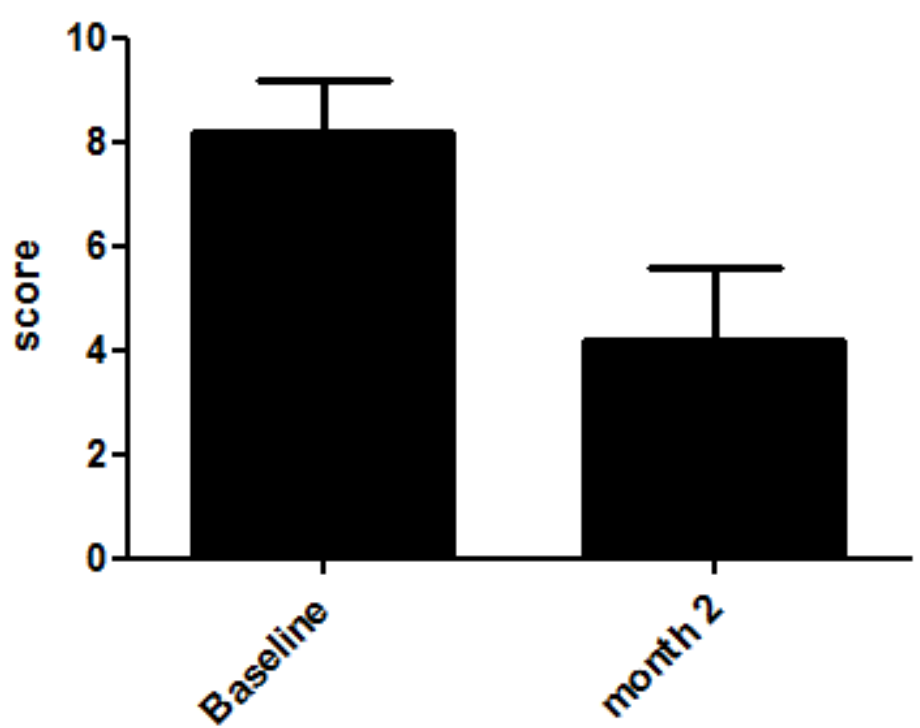

Figure 1. Evolution of IGA score from baseline to month 2.

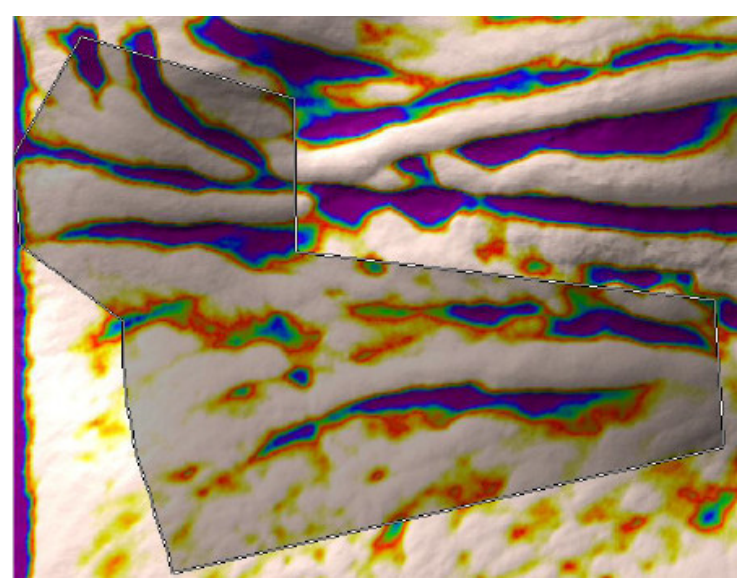

(A)

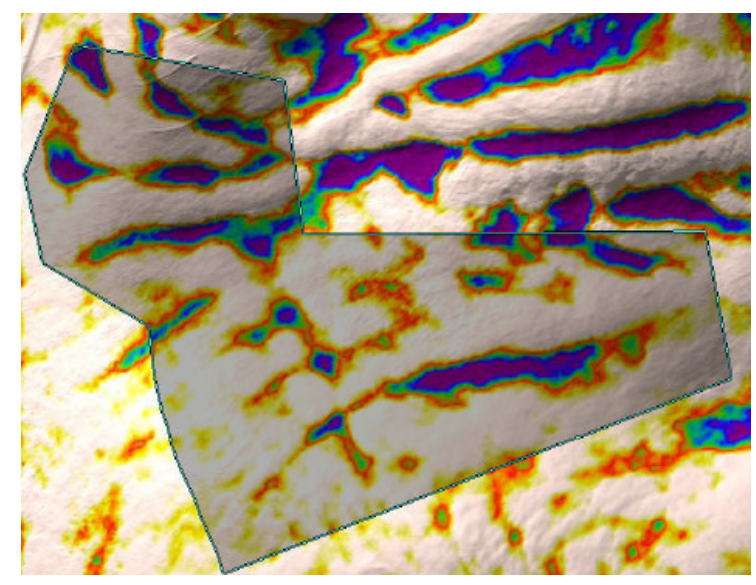

(B)

Figure 2. Coarse wrinkles at baseline (A) and after two months of application of melatonin cream (B). 


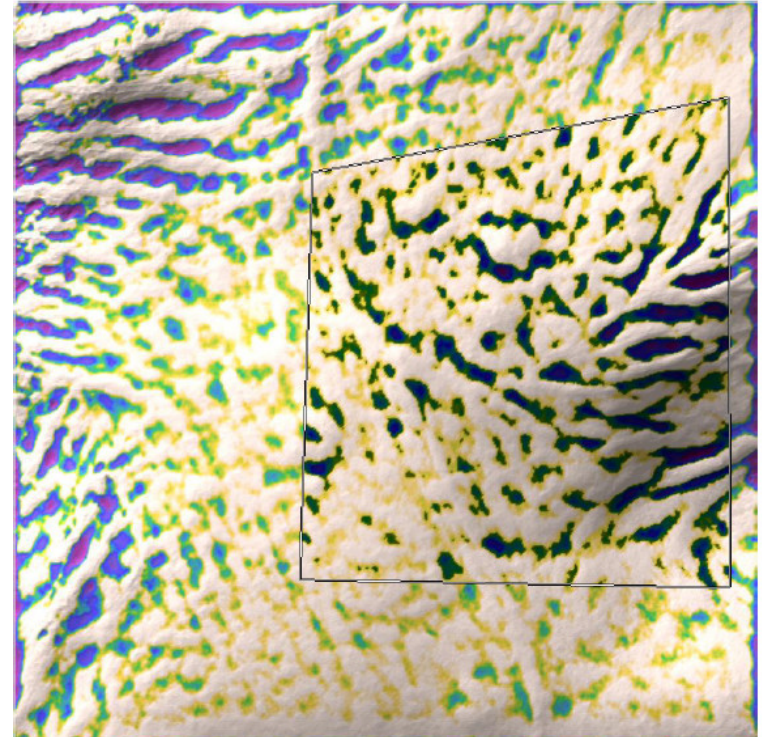

(A)

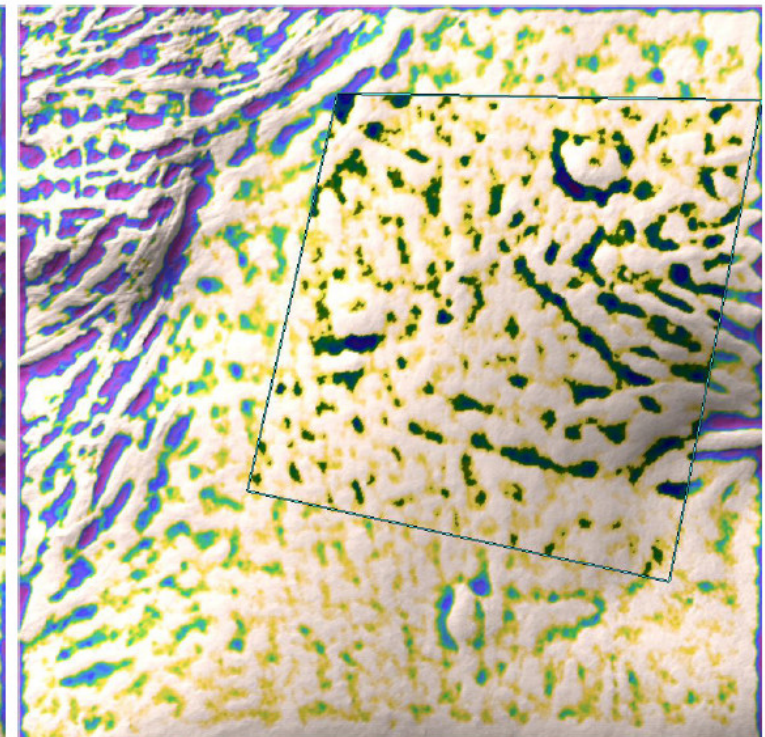

(B)

Figure 3. Fine wrinkles at baseline (A) and after two months of application of melatonin cream (B).

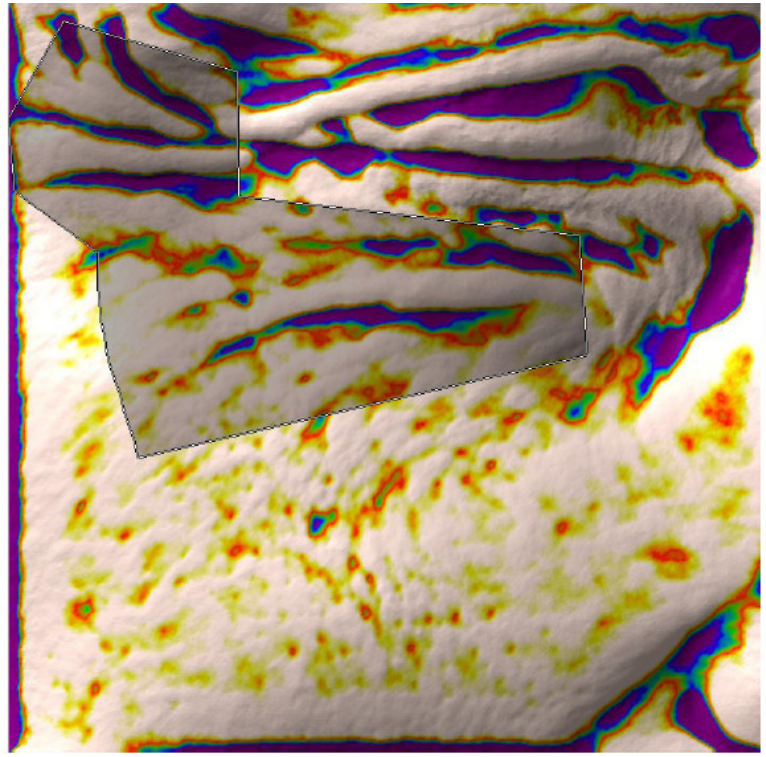

(A)

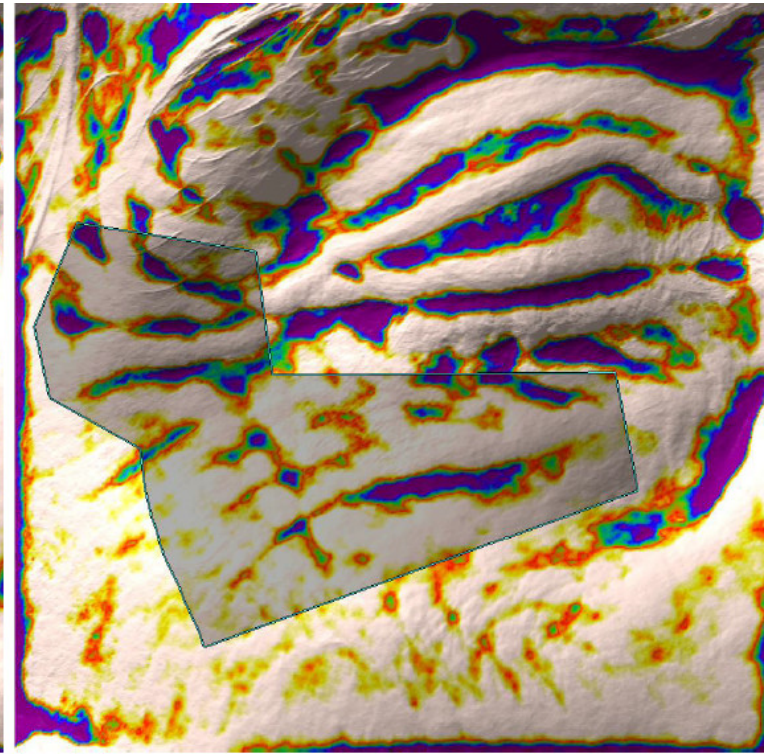

(B)

Figure 4. Periorbital wrinkles at baseline (A) and after two months of application of melatonin cream (B). 


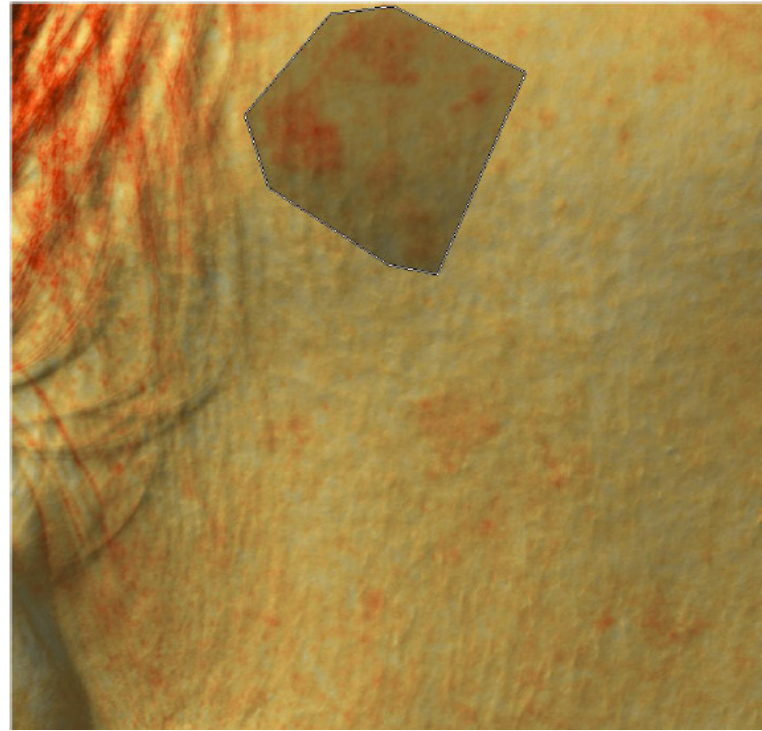

(A)

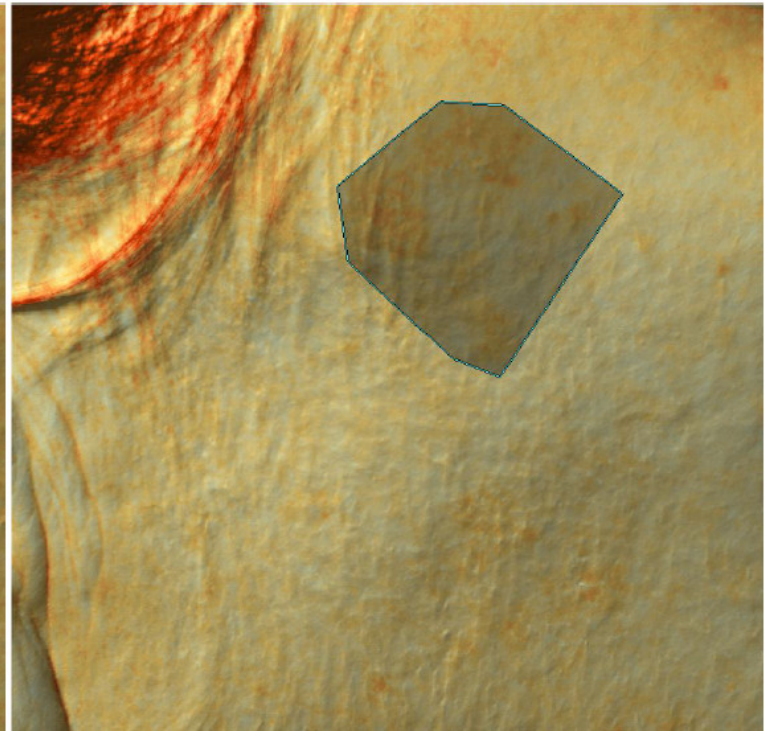

(B)

Figure 5. Melanin content at baseline (A) and after two months treatment with melatonin cream (B).

\section{Discussion}

Mel is a potent anti-inflammatory and antioxidant molecule [26]. In particular, Mel acts as a direct, receptor-independent potent antioxidant [27] The skin can produce and metabolize melatonin [28]. Skin cells also present specific receptors for melatonin (MT1, MT2) [29]. For these reasons, skin is defined as a complete and independent melatoninergic system [30]. At skin level, endogenous melatonin could perform anti-aging and regenerative actions [31]. Mel is also a potent protecting molecule for mitochondria [32,33]. Mitochondrial functional activity declines with age, mainly due to chronic and cumulative oxidative damage [34]. Therefore, the mitochondrial protective action of Mel could slow down the aging process [35,36]. Mel increases the expression of sirtuin 1, counteracting degenerative and pro-apoptotic mechanisms [37]. Mel suppresses ultraviolet (UV)-induced damage in human skin and human-derived cell lines (e.g., keratinocytes and fibroblasts) [38]. Mel-based emulsion for skin photoprotection has recently been developed, showing stable and effective effects [39]. Skin Mel declines with age and therefore the topical supplementation of melatonin could be an interesting anti-skin-aging strategy. A randomized, controlled split-face trial [24] has shown that topical Mel creams (day and a night products) improve clinical signs of skin aging of the face. However, in this trial the primary outcomes were mainly evaluated clinically. So far, no trials have been performed to assess the effect on skin aging parameters of topical Mel by means of objective, operator-independent, instrumental evaluations. In our trial, we evaluated the anti-aging effects of melatonin cream by means of a computerized, operator-independent skin analysis system. The results of the present trial show that topical melatonin can significantly reduce coarse and fine wrinkles. Interestingly, we also documented a reduction in melanin content in the target area. The discovery of Mel by Lerner et al in 1958 [40] was characterized by the fact that this "pineal factor" was able to lighten melanocytes. Some limitations should be taken into account in evaluating our results. We performed an open, non-controlled trial. To increase the internal validity of the trial results, we used an objective procedure to evaluate the efficacy of the tested product (skin wrinkle profilometry and melanin content). Photodamaged skin is characterized by the presence of coarse and fine wrinkles, hyper and hypo pigmentation, roughness and sallowness [41]. The ANTERA 3D CS device could measure all these parameters in a reproducible and sensitive way.

\section{Conclusions}

Topical Mel vehiculated in Melatosphere ${ }^{\mathrm{TM}}$ improves, in the short term, signs of skin aging evaluated clinically and instrumentally in women with mild to moderate skin aging. 
Author Contributions: M.M. and M.P. conceived of the idea of the trial presented. M.P. conducted the subjects' visits and performed the ANTERA evaluation. M.M. supervised the findings of this study. All the authors discussed the results and contributed to the final manuscript.

Funding: This research received no external funding.

Conflicts of Interest: M.M. is an employee of Cantabria Labs Difa Cooper, the company that sells the product evaluated in this study. M.P. declares no conflict of interest.

\section{References}

1. Slominski, A.; Pisarchik, A.; Semak, I.; Sweatman, T.; Wortsman, J.; Szczesniewski, A.; Jing, C. Serotoninergic and melatoninergic systems are fully expressed in human skin. FASEB J. 2002, 16, 896-898. [CrossRef] [PubMed]

2. Slominski, A.T.; Hardeland, R.; Zmijewski, M.A.; Slominski, R.M.; Reiter, R.J.; Paus, R. Melatonin: A cutaneous perspective on its production, metabolism, and functions. J. Investig. Dermatol. 2018, 138, 490-499. [CrossRef] [PubMed]

3. Venegas, C.; García, J.A.; Escames, G.; Ortiz, F.; López, A.; Doerrier, C.; Acuña-Castroviejo, D. Extrapineal melatonin: Analysis of its subcellular distribution and daily fluctuations. J. Pineal Res. 2012, 52, 217-227. [CrossRef] [PubMed]

4. Fischer, T.W.; Slominski, A.; Tobin, D.J.; Paus, R. Melatonin and the hair follicle. J. Pineal Res. 2008, 44, 1-15. [CrossRef] [PubMed]

5. Slominski, A.; Pisarchik, A.; Wortsman, J. Expression of genes coding melatonin and serotonin receptors in rodent skin. Biochim. Biophys. Acta Gene Struct. Exp. 2004, 1680, 67-70. [CrossRef] [PubMed]

6. Pandi-Perumal, S.R.; Srinivasan, V.; Maestroni, G.J.M.; Cardinali, D.P.; Poeggeler, B.; Hardeland, R. Melatonin: Nature's most versatile biological signal? FEBS J. 2006, 273, 2813-2838. [CrossRef] [PubMed]

7. Slominski, A.T.; Zmijewski, M.A.; Semak, I.; Kim, T.K.; Janjetovic, Z.; Slominski, R.M.; Zmijewski, J.W. Melatonin, mitochondria, and the skin. Cell. Mol. Life Sci. 2017, 74, 3913-3925. [CrossRef] [PubMed]

8. Acuna Castroviejo, D.; Lopez, L.C.; Escames, G.; López, A.; Garcia, J.A.; Reiter, R.J. Melatonin-mitochondria interplay in health and disease. Curr. Top. Med. Chem. 2011, 11, 221-240. [CrossRef] [PubMed]

9. Reiter, R.J.; Tan, D.X.; Osuna, C.; Gitto, E. Actions of melatonin in the reduction of oxidative stress. J. Biomed. Sci. 2000, 7, 444-458. [CrossRef] [PubMed]

10. Galano, A.; Tan, D.X.; Reiter, R.J. Melatonin as a natural ally against oxidative stress: A physicochemical examination. J. Pineal Res. 2011, 51, 1-16. [CrossRef] [PubMed]

11. Tan, D.X.; Manchester, L.C.; Reiter, R.J.; Qi, W.B.; Karbownik, M.; Calvo, J.R. Significance of melatonin in antioxidative defense system: Reactions and products. Neurosignals 2000, 9, 137-159. [CrossRef]

12. Tajes, M.; Gutierrez-Cuesta, J.; Ortuno-Sahagun, D.; Camins, A.; Pallàs, M. Anti-aging properties of melatonin in an in vitro murine senescence model: Involvement of the sirtuin 1 pathway. J. Pineal Res. 2009, 47, $228-237$. [CrossRef]

13. Fischer, T.W.; Sweatman, T.W.; Semak, I.; Sayre, R.M.; Wortsman, J.; Slominski, A. Constitutive and UV-induced metabolism of melatonin in keratinocytes and cell-free systems. FASEB J. 2006, 20. [CrossRef]

14. Fischer, T.W.; Slominski, A.; Zmijewski, M.A.; Reiter, R.J.; Paus, R. Melatonin as a major skin protectant: From free radical scavenging to DNA damage repair. Exp. Dermatol. 2008, 17, 713-730. [CrossRef]

15. Janjetovic, Z.; Nahmias, Z.P.; Hanna, S.; Jarrett, S.G.; Kim, T.K.; Reiter, R.J.; Slominski, A.T. Melatonin and its metabolites ameliorate ultraviolet B-induced damage in human epidermal keratinocytes. J. Pineal Res. 2014, 57, 90-102. [CrossRef]

16. Skobowiat, C.; Brożyna, A.A.; Janjetovic, Z.; Jeayeng, S.; Oak, A.S.; Kim, T.K.; Slominski, A.T. Melatonin and its derivatives counteract the ultraviolet $\mathrm{B}$ radiation-induced damage in human and porcine skin ex vivo. J. Pineal Res. 2018, 65. [CrossRef]

17. Rendon, M.I.; Gaviria, J.I. Review of skin-lightening agents. Dermatol. Surg. 2005, 31, 886-890. [CrossRef]

18. Kobayashi, H.; Kromminga, A.; Dunlop, T.W.; Tychsen, B.; Conrad, F.; Suzuki, N.; Paus, R. A role of melatonin in neuroectodermal-mesodermal interactions: The hair follicle synthesizes melatonin and expresses functional melatonin receptors. FASEB J. 2005, 19, 1710-1712. [CrossRef]

19. Slominski, A.T.; Semak, I.; Fischer, T.W.; Kim, T.K.; Kleszczyński, K.; Hardeland, R.; Reiter, R.J. Metabolism of melatonin in the skin: Why is it important? Exp. Dermatol. 2017, 26, 563-568. [CrossRef] 
20. Fischer, T.W.; Kleszczyński, K.; Hardkop, L.H.; Kruse, N.; Zillikens, D. Melatonin enhances antioxidative enzyme gene expression (CAT, GPx, SOD), prevents their UVR-induced depletion, and protects against the formation of DNA damage (8-hydroxy-2'-deoxyguanosine) in ex vivo human skin. J. Pineal Res. 2013, 54, 303-312. [CrossRef]

21. Hardeland, R.; Cardinali, D.P.; Srinivasan, V.; Spence, D.W.; Brown, G.M.; Pandi-Perumal, S.R. Melatonin-A pleiotropic, orchestrating regulator molecule. Prog. Neurobiol. 2011, 93, 350-384.

22. Kleszczynski, K.; Fischer, T.W. Melatonin and human skin aging. Dermato-Endocrinol. 2012, 4, $245-252$.

23. Dubey, V.; Mishra, D.; Asthana, A.; Jain, N.K. Transdermal delivery of a pineal hormone: Melatonin via elastic liposomes. Biomaterials 2006, 27, 3491-3496.

24. Milani, M.; Sparavigna, A. Antiaging efficacy of melatonin-based day and night creams: A randomized, split-face, assessor-blinded proof-of-concept trial. Clin. Cosmet. Investig. Dermatol. 2018, 11, 51-57.

25. Linming, F.; Wei, H.; Anqi, L.; Yuanyu, C.; Heng, X.; Sushmita, P.; Li, L. Comparison of two skin imaging analysis instruments: The VISIA ${ }^{\circledR}$ from Canfield vs the ANTERA 3D ${ }^{\circledR}$ CS from Miravex. Skin Res. Technol. 2018, 24, 3-8.

26. Tan, D.X.; Chen, L.D.; Poeggeler, B.; Manchester, L.C.; Reiter, R.J. Melatonin: A potent, endogenous hydroxyl radical scavenger. Endocr. J. 1993, 1, 57-60.

27. Reiter, R.J.; Tan, D.X.; Maldonado, M.D. Melatonin as an antioxidant: Physiology versus pharmacology. J. Pineal Res. 2005, 39. [CrossRef]

28. Slominski, A.; Wortsman, J.; Tobin, D.J. The cutaneous serotoninergic/melatoninergic system: Securing a place under the sun. FASEB J. 2005, 19. [CrossRef]

29. Dubocovich, M.L.; Markowska, M. Functional MT 1 and MT 2 melatonin receptors in mammals. Endocrine 2005, 27, 101-110.

30. Slominski, A.; Fischer, T.W.; Zmijewski, M.A.; Wortsman, J.; Semak, I.; Zbytek, B.; Tobin, D.J. On the role of melatonin in skin physiology and pathology. Endocrine 2005, 27, 137-147.

31. Majidinia, M.; Sadeghpour, A.; Mehrzadi, S.; Reiter, R.J.; Khatami, N.; Yousefi, B. Melatonin: A pleiotropic molecule that modulates DNA damage response and repair pathways. J. Pineal Res. 2017, 63. [CrossRef]

32. Leon, J.; Acuña-Castroviejo, D.; Escames, G.; Tan, D.X.; Reiter, R.J. Melatonin mitigates mitochondrial malfunction. J. Pineal Res. 2005, 38, 1-9. [CrossRef]

33. López, A.; García, J.A.; Escames, G.; Venegas, C.; Ortiz, F.; López, L.C.; Acuña-Castroviejo, D. Melatonin protects the mitochondria from oxidative damage reducing oxygen consumption, membrane potential, and superoxide anion production. J. Pineal Res. 2009, 46, 188-198. [CrossRef]

34. Balaban, R.S.; Nemoto, S.; Finkel, T. Mitochondria, oxidants, and aging. Cell 2005, 120, 483-495. [CrossRef]

35. Karasek, M.; Reiter, R.J. Melatonin and aging. Neuro Endocrinol. Lett. 2002, 23, 14-16.

36. Armstrong, S.M.; Redman, J.R. Melatonin: A chronobiotic with anti-aging properties? Med. Hypotheses 1991, 34, 300-309. [CrossRef]

37. Chang, H.M.; Wu, U.I.; Lan, C.T. Melatonin preserves longevity protein (sirtuin 1) expression in the hippocampus of total sleep-deprived rats. J. Pineal Res. 2009, 47, 211-220. [CrossRef]

38. Bangha, E.; Elsner, P.; Kistler, G.S. Suppression of UV-induced erythema by topical treatment with melatonin (N-acetyl-5-methoxytryptamine). A dose response study. Arch. Dermatol. Res. 1996, 288, 522-526. [CrossRef]

39. Marto, J.; Ascenso, A.; Gonçalves, L.M.; Gouveia, L.F.; Manteigas, P.; Pinto, P.; Ribeiro, H.M. Melatonin-based pickering emulsion for skin's photoprotection. Drug Deliv. 2016, 23, 1594-1607. [CrossRef]

40. Lerner, A.B.; Case, J.D.; Takahashi, Y.; Lee, T.H.; Mori, W. Isolation of melatonin, a pineal factor that lightens melanocytes. J. Am. Chem. Soc. 1958, 80, 2587. [CrossRef]

41. Griffiths, C.E. The clinical identification and quantification of photodamage. Br. J. Dermatol. 1992, 127, 37-42. [CrossRef] [PubMed]

(C) 2018 by the authors. Licensee MDPI, Basel, Switzerland. This article is an open access article distributed under the terms and conditions of the Creative Commons Attribution (CC BY) license (http:/ / creativecommons.org/licenses/by/4.0/). 